\title{
History of the international societies in health technology assessment: International Society for Technology Assessment in Health Care and Health Technology Assessment International
}

\author{
David Banta \\ Professor Emeritus, University of Maastricht
}

Egon Jonsson

University of Alberta and University of Calgary

\section{Paul Childs}

Health Technology Assessment International (HTAi)

The International Society for Technology Assessment in Health Care (ISTAHC) was formed in 1985. It grew out of the increasing awareness of the international dimensions of health technology assessment (HTA) and the need for new communication methods at the international level. The main function of ISTAHC was to present an annual conference, which gradually grew in size, and also to generally improve in quality from to year. ISTAHC overextended itself financially early in the first decade of the 2000 s and had to cease its existence. A new society, Health Technology Assessment international (HTAi), based on many of the same ideas and people, grew up beginning in the year 2003.

The two societies have played a large role in making the field of HTA visible to people around the world and providing a forum for discussion on the methods and role of HTA.

\section{ISTAHC (INTERNATIONAL SOCIETY FOR TECHNOLOGY ASSESSMENT IN HEALTH CARE 1985-2003)}

The early history of the International Society for Technology Assessment in Health Care (ISTAHC) was described by Banta and Perry in 1997 (1;5-7). A brief summary of that article follows. Rather than focusing on institutions and societal forces, the authors focused on the persons and events that surrounded the birth and growth of the Society.

Starting the early 1970s, many people participated in activities to assess medical technology for health policy and practice. Eventually, this led to the formation of an international society for health technology assessment.

Several publications also contributed not only to the development of health technology assessment (HTA), but significantly to its internationalization. To mention just a few: Archie Cochrane's landmark publication "which showed that decisions about which technologies to implement ought to be guided by evaluation, especially RCTs" (4), and the publication by Bunker et al. on Cost Risks and Benefits of Surgery (3), which proposed that resource use and ethical aspects need to be considered when policy makers and clinicians are forced to make choices about investments in health care. 
The latter book grew from a series of faculty seminars at the Harvard School of Public Health. Some of the people involved in that work eventually became active in the formation of an international society for HTA, for example, Barbara McNeil, and Duncan Neuhauser.

The ground-breaking publications from the Office of Technology Assessment (2, in this issue) played a most influential role in drawing international attention to the field of HTA. People behind the OTA reports were David Banta, Jane Sisk, Clyde Behney, Bryan Luce, Judith Wagner, Kerry Kemp, Jack Langenbrunner, and Hellen Gelband.

Discussions concerning international collaboration in the field took place among groups in the United States and Sweden from the late 1970 s to 1985 . During that time, the first international "journal" or newsletter on HTA (The Sorcerers Apprentice. Available at the secretariat of HTAi) was published quarterly from 1981 to 1984, by the staff of OTA, with Clyde Behney as editor. This initiative was very much appreciated by people around the world interested in "medical technology assessment," which was the term at that time. Within a year, there were more than 100 people listed as subscribers. The title of the newsletter was chosen "to imply the immense, often seemingly magical power that technology can possess." Several contributions to The Sorcerers Apprentice were made by people in different countries such as Iain Chalmers (UK), Tony Culyer (UK), Barbara Stocking (UK), David Martin (Canada), Leo Kaprio (WHO), Per Buch Andreasen (Denmark), Jean-Francois Lacronique (France), Jose Laguna Garcia (Mexico), Paul Gross (Australia), and Duncan Neuhauser, Sy Perry, Stanley Reiser (United States), and the staff of OTA. For the first time, information was collected and shared at an international level among those interested in the field of HTA. Concurrently, from 1982 to 1984, Stanley Reiser and Egon Jonsson developed plans to publish a scientific journal in the field of HTA.

Work on those two publications accelerated the formation of an international society, where Seymour Perry eventually took the lead. Two meetings were particularly instrumental in the formation of an international society. One was held in Washington DC, in June 1982 with eighteen people, including Perry, Banta, Behney, Luce, Reiser, Ruth Hanft (US), and Henry Danielsson (Sweden). The other was held in Stockholm in September the same year and included Perry, Jonsson, Banta, Neuhauser, Bernhard Bloom (United States), and Johannes Vang (Sweden). Banta drew up the preliminary plans for the society. An interim Board was appointed, including Banta, Jonsson, Reiser, Perry, Luce, Hanft, Danielsson, Andreasen, Luigi Donato (Italy), Bruno Horisberger (Switzerland), Lou Groot (Netherlands), Jan Blanpain (Belgium), and Robert Evans (Canada). Vang offered to support the first formal meeting of a society at the offices of WHO Euro in Copenhagen. Banta was asked to develop the program for the first ISTAHC meeting. He approached it by having as many speakers as possible to ensure a maximum attendance.
Table 1. First Board of ISTAHC in 1985 and of HTAi in 2003

ISTAHC 1985

President: Seymour Perry (US)

Vice President: Barbara Stocking (UK)

Secretary: Johannes Vang (Sweden)

Treasurer: Bruno Horisberger (Switzerland)

Directors:

Per Buch Andreasen (Denmark)

David Banta (US)

Luigi Donato (Italy)

Harry Frey (Finland)

Paul Gross (Australia)

Jose Laguna Garcia (Mexico)

Doknic Stefanovic (Yugoslavia)

Judith Wagner (US)

Francis Fagnani (France)

Ex officio: E. Jonsson and S. Reiser

HTAi 2003

President: Chris Henshall (UK)

Vice President: Berit Morland (Norway)

Secretary: Laura Sampietro-Colom (Spain)

Treasurer: Diane Benner (Canada)

Directors:

John Gabbay (UK)

Cliff Goodman (US)

Susan Bidwell (New Zealand)

Andrew Dillon (UK)

Jill Sanders (Canada)

Marjukka Makala (Finland)

Deborah Marshall (Canada)

Wija Oortwijn (Netherlands)

The first meeting of the society was held in 1985 in Copenhagen, with sixty people attending from sixteen countries. Such strong attendance at this initial meeting exceeded the organizers' expectations. At that meeting, the International Society for Technology Assessment in Health Care (ISTAHC) was selected as the name, a constitution was approved, and a board was elected, with Perry as first President (Table 1). The aim of the society was stated as: “. . .encourage research, education, cooperation, and the exchange of information on the clinical and social implications of health care technologies and to foster their optimal use." The Copenhagen meeting was to be followed by eighteen annual ISTAHC meetings up to 2003 (Table 2). Table 3 lists the names of the presidents of ISTAHC and HTAi.

Volunteers, mostly Board members, performed the work of ISTAHC. The first office was placed at George Washington University (Washington, DC) and managed by Seymour Perry and Ruth Hanft. Later, the secretariat moved to Norman Weissman at the University of Alabama, and then to Els Borst Eilers (later appointed as Minister of Health) at the Health Council of the Netherlands. For over a decade, the Society ran solely on the passion and sacrifices of core individuals committed to HTA. By 1996, the then president of ISTAHC had introduced George Toombs as director of a permanent secretariat located in Montreal. 
Table 2. Annual Meetings of ISTAHC and HTAi

\begin{tabular}{l} 
ISTAHC \\
\hline 1985 Copenhagen \\
1986 Washington \\
1987 Rotterdam \\
1988 Boston \\
1989 London \\
1990 Houston \\
1991 Helsinki \\
1992 Vancouver \\
1993 Sorrento \\
1994 Baltimore \\
1995 Stockholm \\
1996 San Francisco \\
1997 Barcelona \\
1998 Ottawa \\
1999 Edinburgh \\
2000 The Hague \\
2001 Philadelphia \\
2002 Berlin \\
2003 Canmore \\
HTAi \\
2004 Krakow \\
2005 Rome \\
2006 Australia \\
2007 Barcelona \\
2008 Montreal \\
2009 Singapore
\end{tabular}

Table 3. Presidents of ISTAHC and HTAi, 1985-2009

\section{ISTAHC}

Seymour Perry (US) 1985-1987

Brian Jennet (UK) 1987-1989

Per Buch Andreasen (Denmark) 1989-1991

Jane Sisk (US) 1991-1993

Tore Schersten (Sweden) 1993-1995

Renaldo Battista (Canada) 1995-1997

Michael Drummond (UK) 1997-1999

David Banta (US) 1999-2001

Alicia Granados (Spain) 2001-2003

HTAi

Chris Henshall (UK) 2003-2005

Berit Morland (Norway) 2005-2007

Reiner Banken (Canada) 2007-2009

Laura Sampietro-Colom (Spain) 2009 -

From 1987 to 2003, ISTAHC produced a quarterly newsletter, edited by David Banta. The newsletter was also translated into Spanish by Jacobo Tieffenberg, a Society board member from Argentina.

ISTAHC grew fairly quickly. By the second meeting a year later, ISTAHC included over 300 members and 2 years later 500 members. By the time of the Stockholm meeting in 1995, ISTAHC included approximately 1,000 members from approximately forty countries. At its peak, ISTAHC included more than 1,500 members.
The Board of ISTAHC eventually believed that its annual meeting was insufficient to deal with the growing complexity, so it began to seek funding from different countries that might not be prepared to undertake a full ISTAHC meeting, but might wish to have a Board meeting in conjunction with a national conference. Such meetings were held in Spain, Israel, China, and Mexico. ISTAHC also supported small regional meetings concerning HTA in several sites, including Cuba and Argentina.

In 1990, ISTAHC received a much appreciated grant from the FHP Foundation of a health maintenance organization (HMO) in southern California run by Robert Gumbiner, who became an active participant in the Society. The grant of 20,000 dollars (USD) per year was to be given to the best (USD10,000) and second best (USD5,000) articles published in the Journal annually over a period of 5 years. The awards also covered travel, accommodation, and registration expenses for the winners. The first award of USD10,000 went to David Eddy in 1991, the second to Iain Chalmers in 1992, the third to Akinori Hishashige in 1993, and the fourth to Gianfranco Domenighetti in 1994. Unfortunately, we have no record on the recipient of the fifth award. In 1995, Alan Williams, then on the board of ISTAHC, successfully raised funds on the order of USD145,000 from PPP Medical trust in the United Kingdom for an international fellowship in HTA. Andreas Laupacis won this award.

During ISTAHC's first decade, much of the discussion by the Board initially circulated around the aims and objectives of the society, membership issues, financing, elections, conference planning, how to provide effective education and training in the field, how to support HTA in developing countries, and how to support research to improve the methodology for assessments. Discussions in the early 1990s continued to focus on some of these issues, but also on joint ventures with other societies, collaboration with the WHO and the World Bank, the development of guidelines, assessment of quality of life, how to provide a forum for agencies in HTA to meet and exchange results (which in 1993 led to the establishment of INAHTA), the formation of a clearinghouse for HTAs, how to collaborate with industry, how to reach out to the general public, HTA at the hospital level, and not the least effective dissemination of findings from research, including the impact of HTAs on health policy and practice.

The ISTAHC meetings were often exciting and intellectually successful and undoubtedly made a strong contribution to the new field of HTA. For a long time, ISTAHC showed consistent growth in both membership and funding. Different programs had been developed and ambitious plans began to be formulated. However, in combination with the cost of running a well-staffed secretariat, the available financial resources were seriously overstretched for all good intentions, and ISTAHC was forced to end its existence in 2003. ISTAHC was reconstituted into a new society, Health Technology Assessment International (HTAi) in 2003. 


\section{HTAi (HEALTH TECHNOLOGY ASSESSMENT INTERNATIONAL): 2003 TO 2009}

HTAi was officially launched in June 2003 at an international HTA conference held in Canmore, Alberta, Canada. Table 1 lists the first members of the HTAi Board.

The first annual business meeting, chaired by Chris Henshall, officially marked the launch of the new Society. The Board subsequently agreed to develop a business plan structured around its primary objective of meeting the needs and expectations of the Society's members. Roles and responsibilities of directors, executive officers, and the secretariat were also outlined, along with an approach for creating three Board subcommittees, each chaired by a Board member: (i) Membership, Communication, Fundraising, and Corporate Relations; (ii) Annual Meetings; and (iii) Scientific and Professional Programs.

The Board further discussed financial projections presented during the annual business meeting and the figures upon which they were based. The meeting concluded with a discussion of the Society's current and future relationships with the International Journal of Technology Assessment in Health Care, local organizing committees of annual meetings, and other professional societies/networks.

\section{Annual Meetings}

Since its inaugural meeting in Krakow, Poland, in 2004, HTAi has held four more annual meetings: in Rome, Adelaide, Barcelona, and Montréal. The sixth HTAi Annual Meeting will be held in Singapore in June 2009. Attendance at HTAi Annual Meetings has been on an upward trend since 2004, the Montréal and Barcelona meetings having the highest attendance with over 800 and 1,000 registered delegates, respectively. Annual Meetings accomplish two important goals for HTAi and its members. First, holding the meeting in locations like Singapore allows HTAi to meets its goal of supporting and promoting the development, communication, understanding, and use of HTA around the world. Second, the scientific program at the Annual Meetings allows HTAi members, the developers, and the users of HTA to share information and insight on an annual basis regarding how to use HTA to improve the provision of health care globally.

\section{Membership}

Membership in HTAi has been generally increasing since 2004, although membership numbers do seem sensitive to where the Annual Meeting is held. The HTAi Board is looking for ways to stabilize and increase the membership of HTAi by providing benefits to members; and, for instance, access to a network of peers and knowledge that is not available elsewhere. Membership categories and fees are also being reviewed to make membership in HTAi as affordable as possible for members around the world. HTAi is also looking for ways to encourage individual and organizational members from South/Central America and the Asia Pacific region, areas where HTA is emerging as important tool in health policy decision making.

\section{Activities}

Along with Annual Meetings HTAi has other ongoing activities, including the following.

Interest Subgroups. Interest Subgroups (ISGs) are groups of HTAi members with an interest in a particular HTA-related topic who would like to explore these topics with their peers by means of Web-based tools available on the HTAi Web site. HTAi currently has five ISGs active with e-mail list servers and shared document areas on the Society's Web site.

HTAi Policy Forum. The HTAi Policy Forum provides a unique opportunity for senior people from public and private sector organizations with strategic interests in HTA to meet one another, members of the HTAi Board, and invited international experts. They can discuss strategic issues concerning the present state of HTA, its development, and implications for healthcare systems, industry, patients, and other stakeholders. The Forum aims to provide an environment where senior people can engage in strategic discussions informed by the perspectives of their different organizations, without the constraints associated with discussions of specific products or organizational policies. The Forum meets twice a year.

\section{Journal}

HTAi recognizes the International Journal of Technology Assessment in Health Care as its official journal. The Journal is, however, independent of the society and is owned by Cambridge University Press, who appoints its editors. For the past 25 years, Egon Jonsson and Stanley Reiser have served as editors. Cambridge University Press publishes the Journal also in electronic form and at a discounted price (paper subscription) for members of HTAi as a benefit of membership. Although HTAi members contribute articles to the Journal, most contributors are not members of HTAi. The Policy Forum has published the outcomes of its deliberations in the Journal. Some members of HTAi serve on the Journal's editorial board. The editor(s), drawing on reviews by the editorial board, manage the content and quality of the Journal to ensure that readers view it as a leading international journal on HTA.

\section{Affiliations}

HTAi is continually exploring ways to build relationships with regional and international HTA bodies. Through agreements based on shared goals, these affiliations can help promote the development of HTA worldwide and provide a broader network of peers and expertise to HTAi members through collaborative relationships and projects. HTAi and INAHTA (International Network of Agencies for Health 
Technology Assessment) signed a Memorandum of Understanding in 2008, agreeing to work together to accomplish common goals.

\section{CONTACT INFORMATION}

David Banta, MD, MPH (HD.Banta@ orange.fr), 9 route de Bragelogne, 10210 Villiers-le-Bois, France

Egon Jonsson, PhD (ejonsson@ihe.ca), Professor, University of Alberta, and University of Calgary, Editor-in-Chief, International Journal of Technology Assessment in Health Care, Executive Director \& CEO, Institute of Health Economics, \#1200, 10405 Jasper Avenue, Edmonton, Alberta T5J 3N4, Canada

Paul Childs, MPH (pchilds@htai.org), Managing Director, Health Technology Assessment International (HTAi), \#1200, 10405 Jasper Avenue, Edmonton, Alberta T5J 2N4, Canada

\section{REFERENCES}

1. Banta HD, Perry S. A history of the International Society for Technology Assessment in Health Care. Int J Technol Assess Health Care. 1997;13:430-453.

2. Banta D, Behney CJ. Office of Technology Assessment health program. Int J Technol Assess Health Care. 2009; 25 (Suppl. 1):28-32.

3. Bunker JP, Barnes BA, Mosteller F. Costs, risks and benefits of surgery. New York: Oxford University Press; 1977.

4. Cochrane A. Effectiveness and efficiency. Random reflections on health services. Nuffield Provincial Hospitals. London: Burgess \& Son, Abingdon Ltd; 1972.

5. Neuhauser D. Commentary. Int J Technol Assess Health Care. 1997;13:454-457.

6. Sisk JE. Commentary. Int J Technol Assess Health Care. 1997; 13:460-462.

7. Stocking B. Commentary. Int J Technol Assess Health Care. 1997;13:458-459. 